\title{
A EDUCAÇÃO DO CAMPO COMO EMANCIPAÇÃO E RESISTÊNCIA: ANÁLISE CRÍTICA DE PROPOSTAS PEDAGÓGICAS DISSIDENTES
}

\author{
The education of the field as emancipation and resistance: critical analysis of \\ dissident pedagogical proposals
}

\author{
Guilherme Gaio Montes \\ Graduando do Curso de Geografia, Bolsista IC da UFJF \\ guilhermegaiomontes@ hotmail.com \\ Vicente Paulo dos Santos Pinto \\ Professor Associado do Departamento de Geociências da UFJF \\ vicente.pinto@ufjf.edu.br
}

Artigo enviado para publicação em 16/08/2019 e aceito em 22/10/2019

DOI: $10.12957 /$ tamoios.2019.43388

\begin{abstract}
Resumo
Este artigo se insere no campo da geografia política em interface com o campo da educação. Concentra-se na identificação e na análise de processos que possam evidenciar resistências possíveis engendradas pelo ambientalismo protagonizado pelos movimentos sociais vinculados à militância da educação do campo e da educação ambiental no âmbito do Brasil. Como experiências concretas são consideradas os Centros Familiares de Formação por Alternância (CEFFAs), as escolas do campo que adotam a metodologia da pedagogia da alternância, as quais estão inseridas no PRONERA (Programa Nacional de Educação na Reforma Agrária). Recorreu-se à revisão de literatura a partir da consulta às plataformas virtuais Google Acadêmico, Scielo, Biblioteca Digital Brasileira de Teses e Dissertações (BDTD), Portal de Teses e Dissertações da Universidade de São Paulo, Banco de Teses da Capes, acerca de artigos, livros, teses e dissertações que têm como centralidade a temática da educação do campo, apoiada na pesquisa sobre o PRONERA, assim como a Pedagogia da Alternância. Como resultado, se propõe estabelecer possíveis relações entre os campos sociais apresentados, procurando fornecer uma análise sintética de experiências educacionais e suas potencialidades para propostas educativas voltadas para o desenvolvimento socioespacial e para a transformação social.
\end{abstract}

Palavras-chave: Ambientalismo; Emancipação; Educação do Campo; Propostas pedagógicas; Resistência.

\begin{abstract}
This article is inserted in the field of political geography in interface as field of education. It focuses on the search for identification and analysis of processes that may evidence possible resistances engendered by environmentalism carried out by social movements linked to the militancy of rural education and environmental education within Brazil. As concrete experiences are considered the Family Centers of Training by Alternation (CEFFAs), the schools of the field that adopt the methodology of the pedagogy of alternation, which are inserted in the National Program of Education in Agrarian Reform. Literature review was done using the virtual platforms Google Academic, Scielo, Brazilian Digital Library of Theses and Dissertations (BDTD), Thesis and Dissertations Portal of the University of São Paulo, Capes Bank of Theses, about articles, books, theses and dissertations that have as centrality the thematic of the education of the field, supported in the research on the PRONERA, as well as the Pedagogy of the Alternation. As a result, it is proposed to establish possible relationships among the social fields presented, seeking to establish a synthetic analysis of educational experiences and their potentialities for educational proposals focused on socio-spatial development and social transformation.
\end{abstract}

Keywords: Environmentalism; Emancipation; Field Education; Pedagogical proposals; Resistance. 


\section{Introdução}

O sistema educacional no Brasil passou por diversas mudanças ao longo do tempo, sempre se adaptando às novas exigências do capitalismo como sistema hegemônico. Durante os dois séculos passados, o Estado passou a controlar e centralizar o sistema educacional e, consequentemente, padronizar o conteúdo escolar em prol do atendimento à demanda do setor produtivo industrial, além do desenvolvimento do próprio raciocínio científico, que irá dominar até os dias atuais. As consequências desta evolução são o atual modelo educacional, de divisão do conteúdo em séries e em diferentes disciplinas, treinamento metodológico do professor de como passar os conteúdos e avaliações de desempenho para os estudantes.

Atualmente, de modo geral, as propostas de políticas educacionais tendem, cada vez mais, para uma descentralização, além do investimento, cada vez maior, de agências internacionais como o Banco Mundial e de outros agentes neoliberais. A justificativa de investimentos em estratégias e modelos educacionais se pauta na tentativa de um aumento na eficiência e diminuição da burocracia estatal. Segundo Fernandes \& Tarlau (2017), existem três fatores que contribuíram para a formação da atual conjuntura educacional: $1^{\circ}$ ) uso da teoria do capital humano; $2^{\circ}$ ) o desenvolvimento de um estudo de taxa de retorno à educação; e $3^{\circ}$ ) a crise da dívida internacional que obrigou os países do hemisfério sul a "neoliberalizar" sua economia em troca de empréstimos a estas agências (FERNANDES \& TARLAU, 2017, p. 553).

É importante entender a educação numa perspectiva territorial, associando-a ao desenvolvimento nacional, às transformações socioespaciais e à superação das desigualdades sociais. Em geral, as instituições multilaterais tendem a tratar de forma separada território e escola, pois não se exige ou não se tem interesse de exigir, por parte delas, uma transformação ou uma evolução da sociedade.

Em contrapartida, Fernandes \& Tarlau (2017, p. 556) argumentam que o Estado e as comunidades são instituições territorializadas fundamentais para cuidar da educação, porque não podem separá-la do território em que está inserida. Defendem que as instituições precisam ter vínculos territoriais com a escola, não ignorando os princípios e valores da comunidade.

A educação do campo se destaca por ser ontologicamente "indissociável" (utilizando o termo proposto por Fernandes \&Tarlau) do território. Portanto, uma análise da educação do campo possibilita "compreendermos os vínculos entre educação e território, porque um não existe sem o outro. Toda educação produz um território e por ele é produzida" (FERNANDES \& TARLAU, 2017, p. 556).

A educação do campo, desde sua origem, caminha junto às propostas de educação ambiental crítica ou emancipatória, como será exposto ao longo do texto, mas buscando uma abordagem mais prática da realidade do camponês, questionando o sistema políticoeducacional hegemônico, além de propor diferentes interpretações da realidade e da própria natureza (CALDART, 2009). Assim, a educação do campo revela conflitos de territorialidades entre projetos culturais e civilizatórios alternativos, confrontados por seus interesses na apropriação da natureza, entre o poder hegemônico do sistema-mundo e a emancipação dos povos com seus próprios saberes ambientais (LEFF, 2016).

A geografia, a partir desta conjuntura, irá sofrer influências dos movimentos ambientalistas, da educação ambiental e da educação do campo. Mendonça (2012) relaciona geografia e meio ambiente dividindo a história do pensamento geográfico em dois momentos: o "ambientalismo geográfico de cunho naturalista" e o "ambientalismo geográfico engajado na transformação da realidade”. Este segundo período, como argumenta Mendonça (2012), teve inspiração do marxismo, e foi extremamente voltado 
para o estudo do espaço, tendo como base a compreensão das relações sociais de produção e sua relação com a estrutura de classes sociais e obtenção de mais valia. Ainda, a princípio, não houve preocupação desta linha de pensamento marxista da geografia com a problemática ambiental e, quando o fez, fez de maneira bastante limitada.

Relativizando a distância entre marxismo e ambientalismo, pode-se constatar que vários conceitos da geografia podem ser trabalhados para analisar a complexidade do campo atual, inclusive no "ambientalismo geográfico engajado na transformação da realidade". Dialogando, primeiramente com os princípios básicos de espaço para a geografia crítica/radical, Lefebvre (2006) propõe que o espaço seja produto das relações sociais e espaciais, produzido por sujeitos sociais, realizado nas práticas socioespaciais.

A partir desta interpretação de espaço e da meta de transformação social presente dentro da geografia crítica, pode ser considerado o conceito de desenvolvimento sócioespacial (SOUZA, 2013), o qual busca teorias que fujam de modelos já estabelecidos e puramente econômicos, propondo um modelo de desenvolvimento totalmente aberto, com o objetivo de busca de uma transformação da sociedade, sendo por base promovida por ela mesma.

Na opinião de Souza (2013) a busca por uma sociedade autônoma e pela superação da heteronomia ${ }^{1}$ sugere que sejam construídos "espaços de resistência". Construção esta, estabelecida tanto pela política, quanto pela cultura e, até, pela economia.

Estes espaços são conceituados por Souza (2013) como "territórios dissidentes". Territórios que, na sua concepção, irão questionar e contestar o status quo hegemônico. Este conceito também dialoga com os conceitos de "contra espaço" (MOREIRA, 2012), "heterotopia" (FOUCAULT, 2013) e "economia solidária" (MENDES \& ORTIGOZA, 2015).

Dentro desta perspectiva de análise, como será mostrado ao longo deste texto, defende-se a ideia de que as escolas do campo possam ser também compreendidas como "territórios dissidentes", "contra espaços", "heterotopias" ou "economias solidárias", visto que sua origem é marcada por reivindicações práticas dos trabalhadores do campo e por uma visão educacional que irá se contrapor à hegemônica implantada (CALDART, 2009).

Ao mesmo tempo, foram estabelecidas no Brasil políticas públicas que repercutem diferentes propostas metodológicas e práticas pedagógicas que buscam afirmar princípios e valores voltados ao povo do campo, dentre elas, o PRONERA (Programa Nacional de Educação na Reforma Agrária) e os Centros Familiares de Formação por Alternância (CEFFAs).

Neste artigo, pretende-se analisar tais metodologias e práticas, para além da educação ambiental e da educação do campo, buscando-se a relação entre as práticas e os conceitos da geografia crítica, procurando-se fazer uma análise de tais experiências educacionais e suas potencialidades para um desenvolvimento socioespacial e de transformação social.

A primeira parte do texto está direcionada a propor uma relação entre o ambientalismo, a educação ambiental e a educação do campo, com ênfase nas articulações destes campos sociais com a geografia. Na segunda parte é realizada uma análise crítica de propostas pedagógicas dissidentes.

\section{Ambientalismo, Educação Ambiental e Educação do Campo: articulações com a geografia como emancipação e resistência}

O movimento ambientalista surgiu a partir dos anos 1970 entre as classes médias intelectualizadas e tinha como finalidade a aceitação de suas ideias e de sua identidade 
enquanto grupo. Entretanto, com o passar dos anos, passou a construir um diálogo com outros segmentos sociais, criando um movimento social portador de um projeto de transformação da sociedade como um todo. Este movimento, de forma geral, propõe uma ideologia que se contrapõe a da sociedade capitalista de produção, questionando o modo de vida atual da sociedade, atraindo uma diversa quantidade de críticos do status atual, assim como de céticos (TRES, 2006).

Alier (2007) divide o movimento ambientalista em três grandes correntes principais: "o culto à vida silvestre", "o evangelho da ecoeficiência" e "o ecologismo dos pobres". Dentro deste contexto histórico e temático, a educação ambiental propriamente dita, nasce como um subcampo do movimento ambientalista (ao mesmo tempo em que mantém uma autonomia) em meio à emergência de uma crise ambiental a partir da segunda metade do século XX. A educação ambiental, ao longo de sua consolidação, foi adquirindo diferentes visões dentro do universo pedagógico, buscando sempre uma relação diferenciada entre homem-sociedade-educação-natureza e "estruturou-se como fruto de uma demanda para que o ser humano adotasse uma visão de mundo e uma prática social capazes de minimizar os impactos ambientais então prevalecentes" (LAYRARGUES \& LIMA, 2011, p. 5).

A primeira visão concebida de educação ambiental foi a chamada conservacionista, a qual buscava o despertar de uma nova sensibilidade humana perante à natureza, "desenvolvendo-se a lógica do 'conhecer para amar, amar para preservar', orientada pela conscientização 'ecológica' e tendo por base a ciência ecológica”. Tal visão era totalmente desprovida de algum tipo de politização ou busca por transformação social, pois foi formada tendo por base que os problemas ambientais eram inevitáveis frente à modernização constante (LAYRARGUES \& LIMA, 2011, p.5).

Mais tarde surgiu uma derivação da visão conservacionista, a chamada pragmática, sendo agora adaptada à visão neoliberal contemporânea, abrangendo:

[...] sobretudo as correntes da Educação para o Desenvolvimento Sustentável e para o Consumo Sustentável, é expressão do ambientalismo de resultados, do pragmatismo contemporâneo e do ecologismo de mercado que decorrem da hegemonia neoliberal instituída mundialmente desde a década de 1980 e no contexto brasileiro desde o governo Collor de Mello nos anos 1990 (LAYRARGUES \& LIMA, 2011, p. 9)

Se contrapondo a estas duas correntes, se constitui a macrotendência políticopedagógica da educação ambiental reconhecida como crítica, emancipatória, transformadores, popular. Esta, surgida no começo dos anos 1990, se destaca pois para os apoiadores de tal corrente, "não bastava lutar por uma nova cultura na relação entre ser humano e natureza, sem ao mesmo tempo lutar por uma nova sociedade" (LAYRARGUES \& LIMA, 2011, p. 7). Ou seja, buscava-se uma mudança radical que pudesse transformar o próprio conhecimento, as instituições, as relações sociais e políticas, os valores culturais e éticos.

\footnotetext{
Essa nova opção pedagógica se nutriu do pensamento Freireano, dos princípios da Educação Popular e de autores marxistas e neomarxistas que pregavam a necessidade de incluir no debate ambiental a compreensão político-ideológica dos mecanismos da reprodução social, de que a relação entre o ser humano e a natureza é mediada por relações socioculturais e de classes historicamente construídas (LAYRARGUES \& LIMA, 2011, p. 8).
}

A educação do campo surge atrelada à educação ambiental crítica ou emancipatória, mas buscando uma abordagem mais prática da realidade do camponês, questionando o sistema/política educacional hegemônico, além de diferentes 
interpretações da realidade e da própria natureza (CALDART, 2009). Assim, a educação do campo revela conflitos de territorialidades entre projetos culturais e civilizatórios alternativos, confrontados por seus interesses na apropriação da natureza, entre o poder hegemônico do sistema-mundo e a emancipação dos povos com seus próprios saberes ambientais (LEFF, 2016).

A geografia, a partir deste contexto histórico, assim como influencia, também vai sofrer influências dos movimentos ambientalistas, da educação ambiental e do campo. Principalmente, a partir da segunda metade do século XX, pois em meio à crise ambiental implantada, de maneira geral, os diferentes campos científicos, tais como a geografia, a educação, a biologia, a química, a física, as ciências sociais são desafiados a contribuir com o debate da questão da crise ambiental. Em meio a todas estas ciências, a geografia se destaca como "a única ciência que desde sua formação se propôs ao estudo da relação entre os homens e o meio natural do planeta" (MENDONÇA, 2012. p. 22). Dentre os teóricos da geografia que priorizam as práticas socioespaciais na busca de uma transformação social, Souza (2013) se destaca com sua teoria sobre desenvolvimento, na qual está proposta a fuga de modelos já estabelecidos e puramente econômicos. O conceito de "desenvolvimento sócio espacial" propõe um modelo de desenvolvimento totalmente aberto, com o objetivo de buscar a transformação da sociedade. Esta abordagem utiliza como base a "macroteoria aberta" do desenvolvimento socioespacial, "fundada filosoficamente sobre o princípio de autonomia" (SOUZA, 2013, p. 262).

Sobre a noção de autonomia, dentre diversos autores, se destaca a de Cornelius Castoriadis. Segundo Martins (2002), a autonomia defendida por Castoriadis é um projeto revolucionário que visa à autonomia de todos, a partir da crise da sociedade, por meio da contestação dos sujeitos que nela vive; em seu projeto relaciona com a práxis, pois para o autor ela é o processo que garante a autonomia.

No que se refere à origem do termo práxis e à forma em que Marx o atribui, a práxis pode ser buscada na Grécia antiga. Conforme Konder (1992 apud BATISTA, 2007, p. 174), "para Aristóteles existiam três tipos de atividades humanas fundamentais: a práxis, a poiésis, e a theoria". A práxis era interpretada como atividade ética e política; a atividade produtiva era a chamada poiésis e, por último, a theoria era exclusivamente a busca pela verdade.

\begin{abstract}
A práxis no sentido que Marx atribui, ação transformadora revolucionária, transcendente a condição de simples ação. Contudo, não expressa qualquer ação transformadora, posto que está aprofundada numa concepção dialética da história e da sociedade, une pensamento consciente e ação real, com vistas a transformação radical da sociedade. Isso porque, a práxis torna possível a passagem da teoria à prática, essencialmente, uma prática transformadora, revolucionária. (BATISTA, 2007, p.177)
\end{abstract}

Buscando articular estas categorias com o conceito de desenvolvimento, proposto por Souza (2013, p.264), o mesmo coloca a teoria como algo que promova uma "transformação social para melhor, propiciadora de melhor qualidade de vida e maior justiça social". A qualidade de vida aqui é entendida como a satisfação de necessidades materiais e imateriais (que variam de acordo com a época), e justiça social, como aquilo ligado a questões de simetria, equidade e igualdade efetiva de oportunidades.

Essa transformação social para melhor se concretizaria a partir da busca constante da conquista da autonomia plena da sociedade, além da superação da heteronomia como assimetria estrutural de poder entre dirigentes e dirigidos, dominantes e dominados (SOUZA, 2013).

Souza divide o conceito de autonomia de dois modos: 
[...] autonomia individual (capacidade individual de decidir com conhecimento de causa e lucidamente, e perseguir a própria felicidade livre de opressão) e autonomia coletiva (que compreende tanto a auto instituição lúcida da sociedade, em que o fundamento das "leis" não é metafísico, mas sim a vontade consciente dos homens e mulheres, quanto à existência de instituições garantidoras de um acesso realmente igualitário aos processos de tomada de decisão sobre os assuntos de interesse coletivo) (SOUZA, 2013, p.265).

A busca por uma sociedade autônoma e pela superação da heteronomia sugere que sejam construídos "espaços de resistência" ou "territórios dissidentes", questionadores e contestadores do status quo:

Há um imenso potencial para que esses espaços atuem e continuem a atuar como ambientes de gestação de "utopias experimentais": utopia não como "fantasia irrealizável”, mas sim como metas testáveis e aprimoráveis por meio da práxis. Territórios, enfim, de experimentação anti-heterônoma. Autênticos "laboratórios" da... autonomia (SOUZA, 2013, p.300).

Como já foi afirmado, o conceito de territórios dissidentes dialoga com ode "contra espaço" trazido por Moreira (2012), que se dá quando uma determinada parte da sociedade se levanta contra a ordem do espaço dominante que está imposta, gerando o contra espaço em relação ao espaço, indissociáveis, ou seja: um não existe sem o contraponto do outro. Segundo Moreira:

É contra espaço o arranjo espacial de uma greve de operários, uma ocupação de terra com fim de assentamento, o surgimento de uma favela, um ritual de capoeira ou de candomblé, a luta pelo direito à cidade, uma manifestação de rua, um movimento de embargo de uma obra de efeito ambiental de uma comunidade, mas também, a segregação urbana da classe média, o embargo territorial de setores de dominantes excluídos do bloco de poder instituído como governo central dentro do bloco histórico (MOREIRA, 2012, p. 217).

Outro conceito que agrega e ajuda a entender o significado de território dissidente é o de heterotopia de Foucault (2013), sendo esta uma "contra utopia", na qual a utopia representa o "irreal" e a heterotopia o "real". Na interpretação de Oliveira $(2018$, p.80) a heterotopia está presente no espaço onde a vida se dá, o espaço das relações de proximidade, ou seja, "uma ação, uma prática socioespacial, que ocupa um determinado espaço, no qual não deveria estar". Segundo o autor:

[...] heterotopia, somente será compreendido na trama das relações existentes no espaço e no contexto das práticas espaciais insurgentes. Dessa maneira, os espaços heterótopos são os espaços não-hegemônicos, são espaços de produção de horizontalidades, de coletividades, contrários aos processos de heteronomia, uma vez que se aproximam das práticas autônomas (OLIVEIRA, 2018, p.80).

O território dissidente se relaciona com o conceito de heterotopia a partir do fato de que o primeiro, nos dizeres do próprio Souza (2010), seria um tipo de "heterotopia emancipatória" propiciada pela práxis. Segundo Souza (2010, p.24) "territórios dissidentes ou centros sociais são um tipo de heterotopia, para empregar o interessante e vago termo proposto por Foucault (2006) - mais especificamente, um tipo que se poderia chamar de heterotopia emancipatória".

Outro conceito que é importante ser destacado neste contexto é o de "economia solidária" trazido aqui por Mendes \& Ortigoza (2015), que, como os outros, também se 
aproxima de "território dissidente", pois se refere à construção de um espaço que se contrapõe ao dominante/hegemônico. Para Mendes e Ortigoza:

\begin{abstract}
Os territórios onde se desenvolvem as práticas em Economia Solidária são aquelas produzidas pela comunidade e que não se deixam dominar pela ordem hegemônica capitalista. Assim sendo, tais territórios, dialeticamente, geram uma desordem no sistema dominante, com o fito de estabelecer uma nova ordem, tornando-se, portanto, territórios da subversão (MENDES \& ORTIGOZA, 2015, p.5)
\end{abstract}

Dentro desta perspectiva de análise, abrem-se brechas para se pensar as escolas do campo como "territórios dissidentes", "contra espaços", "heterotopias" ou "economias solidárias".

De acordo com Caldart (2009), desde sua origem, as escolas do campo apresentaram objetivos e fins práticos. Primeiramente, a luta pelo acesso e pela democratização da educação para trabalhadores do campo. Depois, a crítica a uma proposta genérica de educação brasileira, tendo como reinvindicação uma educação que se adequasse à sua própria realidade camponesa, uma educação "DO campo" (grifo nosso). E, por fim, o nascimento desta educação do campo teve origem em áreas de luta pela reforma agrária, principalmente, com o protagonismo de movimentos sociais camponeses como o Movimento dos Trabalhadores Sem Terra (MST).

\begin{abstract}
A educação do campo é um movimento real de combate ao "atual estado das coisas": movimento prático, de objetivos e fins práticos, de ferramentas práticas, que expressa e produz concepções teóricas, críticas a determinadas visões de educação, de política de educação, de projetos de campo e de país, mas que são intepretações da realidade construídas em vista de orientar ações/lutas concretas (CALDART, 2009, p.40).
\end{abstract}

Esta crítica prática acabou se tornando teórica de base marxista, por meio de suas concepções de teoria crítica e práxis revolucionária. Pode-se dizer que "a educação do campo não nasceu como uma crítica apenas de denúncia: já que surgiu como contraponto de práticas, construções de alternativas, de políticas, como crítica projetiva de transformações" (CALDART, 2009, p.40).

Sendo assim, a educação do campo pode ser um possível foco de emancipação e resistência por parte dos sujeitos que estão nela inseridos pois, como já destacado, revela conflitos de territorialidades entre projetos culturais e civilizatórios alternativos, confrontados por seus interesses na apropriação da natureza, entre o poder hegemônico do sistema-mundo e a emancipação dos povos com seus próprios saberes ambientais (LEFF, 2016).

Feita esta análise mais conceitual do ambientalismo, da educação ambiental, e da educação do campo, buscando-se articulações com a geografia e suas potencialidades como emancipação e resistência, desdobra-se a tentativa de apresentar propostas pedagógicas dissidentes. Propostas estas, que exemplificam de maneira mais prática e concreta, evidências de resistências possíveis engendradas pelos movimentos sociais vinculados à educação do campo no Brasil.

Sendo assim, na seção seguinte, pretende-se analisar de forma mais detalhada, o PRONERA (Programa Nacional de Educação na Reforma Agrária) e a metodologia da pedagogia da alternância, considerando os Centros Familiares de Formação por Alternância (CEFFAs), institucionalizados a partir do decreto $n^{\circ} 7.352$, de 4 de novembro de 2010, que dispõe sobre a atual política de educação do campo. 


\section{Na busca de uma análise crítica de propostas pedagógicas dissidentes: o PRONERA - Programa Nacional de Educação na Reforma Agrária e os Centros Familiares de Formação por Alternância (CEFFAs)}

O Decreto $\mathrm{n}^{\circ} 7.352$ de 04 de novembro de 2010 dispõe sobre a política de educação do campo e o Programa Nacional de Educação na Reforma Agrária PRONERA (SECADI, 2012). Este decreto surgiu em resposta a uma série de demandas dos movimentos sociais vinculados à luta do campo no sentido de reivindicar uma educação que se adequasse às realidades do povo camponês e vai propor uma série de estratégias, como as duas propostas apresentadas a seguir.

\section{O PRONERA - Programa Nacional de Educação na Reforma Agrária:}

O Programa Nacional de Educação na Reforma Agrária (PRONERA) é uma política pública educacional que surge por meio do setor de educação do Movimento dos Trabalhadores Sem Terra (MST), o qual em 1997 promoveu o I Encontro Nacional de Educadores/as da Reforma Agrária - ENERA. Este encontro resultou em uma ampla participação da sociedade civil com diversas parcerias com Universidades, entidades estrangeiras e ONGs. Em 1998, estas discussões resultaram no Programa Nacional de Educação na Reforma Agrária (PRONERA) instituído em 16 de abril de 1998 pelo Ministério Extraordinário de Política Fundiária, por meio da Portaria n 10/98.

Esta política resultou de uma ostensiva demanda dos trabalhadores rurais e do campo, os quais na época estavam em uma situação deficitária de oferta educacional pela ausência de uma política pública específica para estes povos (CARNEIRO et.al., 2016). Os objetivos do programa, segundo o atual Manual de operações:

\footnotetext{
Oferecer educação formal aos jovens e adultos do programa Nacional de Reforma Agrária (PNRA) em todos os níveis e áreas de conhecimento; melhorar o acesso a educação dos beneficiários do PNRA; proporcionar melhoria no desenvolvimento dos assentamentos através da qualificação profissional e técnica. (BRASIL/INCRA, 2014, p.17)
}

Assim, o PRONERA foi a primeira política pública feita e elaborada por e para os trabalhadores do campo, nascida por meio da participação e reivindicação ativa dos movimentos sociais do campo e da organização coletiva dos trabalhadores. Segundo Santos \& Silva (2017):

\footnotetext{
O PRONERA significou de certa forma uma ruptura de paradigma, pois além de não existirem políticas educacionais para o campo as ações que eram pensadas não estavam de acordo com a realidade e necessidade dos sujeitos do campo e tão pouco tinha participação dos sujeitos do campo em suas elaborações. (SANTOS \& SILVA, 2017, p. 4)
}

A partir da instituição do PRONERA, criou-se uma verdadeira disputa para a democratização do saber, com o surgimento de novas ideias ou ideais que irão confrontar uma lógica já posta e que, ao mesmo tempo, dá visibilidade aos povos do campo para que eles tenham e reivindiquem seus direitos não somente pela terra e educação, mas também direito à segurança e boa qualidade de vida (SANTOS \& SILVA, 2017). Assim:

O PRONERA passa a ser então uma prática educativa contra-hegemônica que vai contra uma lógica dicotômica que diz que uns nascem para o trabalho manual enquanto outros enquanto outros nascem para o trabalho intelectual; torna-se um instrumento de resistência. Mais que permanência e acesso a 
educação, o PRONERA em todos os seus anos e ações busca assegurar e promover a expansão de direitos no qual representa para os movimentos sociais do campo um instrumento de luta em prol da conquista da terra, ao território a produção e manutenção da vida "é um instrumento de resistência [...] que constitui sujeitos coletivos conscientes de seu papel histórico e social" (II PENERA, 2015, p.9). (SANTOS E SILVA, 2017, p. 5)

Por ter estas características, o PRONERA dialoga com vários conceitos da geografia, pois os povos do campo, a partir dele, criam condições para um desenvolvimento socioespacial que irá se contrapor a uma educação hegemônica criando, consequentemente, espaços de resistência ou "territórios dissidentes" como proposto por Marcelo Lopes de Souza, assim como, "espaços de economias solidárias", "heterotopia" e "contra espaços" como já proposto neste texto.

\section{OS Centros Familiares de Formação por Alternância (CEFFAs) e a Pedagogia da Alternância}

Como dito por Caldart (2004), nos últimos anos travou-se uma verdadeira guerra, junto com os movimentos sociais do campo, inclusive na formação das bases legais da educação brasileira, para se formar uma educação que garantisse não somente o acesso, mas a construção de uma educação DO (grifo nosso) campo - que afirmasse o direito da população de ser educada onde ela vive, sendo pensada e construída a partir deles próprios, vinculada a sua cultura e suas necessidades humanas e sociais, resistindo e se contrapondo à modernização da agricultura e da educação brasileira. Do mesmo modo, surgiu concomitantemente uma luta pela transformação das condições sociais de vida no campo, vinculando assim a luta pela educação às lutas sociais.

Campo é concebido como um espaço social com vida, identidade cultural própria e práticas compartilhadas por aqueles que ali vivem. E, sendo assim, a educação do campo deve refletir a vida, os interesses e as necessidades de desenvolvimento dos seus sujeitos sociais (SILVA, 2015, p.145)

Dentro deste contexto têm surgido no Brasil diferentes metodologias/práticas pedagógicas que buscam afirmar os princípios, práticas e valores voltadas ao povo do campo, dentre elas os Centros Familiares de Formação por Alternância (CEFFAs) - que disseminaram a metodologia da alternância por todo o país, sendo inclusive incluída em políticas públicas como uma alternativa de proposta de formação dos sujeitos do campo, e institucionalizada no Decreto $\mathrm{n}^{\circ} 7.352$ de 04 de novembro de 2010 que dispõe sobre a política de educação do campo e o Programa Nacional de Educação na Reforma Agrária - PRONERA (SECADI, 2012).

Segundo Humberto Rodrigues de Lima et. al. (2013), a pedagogia da alternância surgiu na França nos anos 1930 em meio à reestruturação pós Primeira Guerra Mundial, quando o país passava por uma grave crise humanitária de pobreza e reorganização econômica. Em meio a esta crise, um grupo de trabalhadores rurais percebeu que a educação ofertada nas cidades não se apresentava efetiva para a educação dos seus filhos. Assim:

Era primordial que a educação valorizasse o conhecimento da terra e sua relevância para a população rural. As condições adversas fomentaram para que o grupo de pais buscassem alternativas para educar seus filhos dentro das necessidades do campo. Os conteúdos das escolas das cidades não atendiam as especificidades rurais. Além do desgaste por parte dos alunos em se deslocar 
diariamente distâncias significativas, que em muitas vezes os impossibilitam em ajudar seus pais no cuidado da terra, forçando os a escolher, entre estudar ou trabalhar (LIMA et. al., 2013, p. 2969)

Esta organização de pais, junto com a igreja, possibilitaram a formação de uma nova metodologia construída e direcionada desde a base para os jovens do campo, sendo esta a Pedagogia da Alternância (LIMA et. al., 2013). Esta proposta de educação elaborada no campo e para o campo logo se espalhou para outros países em todo o mundo, inclusive para o Brasil.

Segundo o relatório pedido pela Secretaria de Educação Continuada, Alfabetização e Diversidade - SECAD/MEC, resultando no parecer CNE/CEB $N^{\circ} 1$, de 02 de Fevereiro de 2006, no Brasil, a Pedagogia da Alternância, junto com os Centros Familiares de Formação por alternância (CEFFAs), foram implantados em 1969, no Espírito Santo, sendo depois expandido para os outros estados da nação. Para o relator, a alternância mais efetiva é a que associa meios de vida sócio profissional e escolar em uma unidade de tempos formativos, consistindo em oito diferentes formas de organização (SECADI, 2012).

As experiências da Pedagogia da Alternância, com base em Queiroz (2004), são: Escolas Famílias Agrícolas (EFA); Casas Familiares Rurais (CFR); Escolas Comunitárias Rurais (ECOR); Escolas de Assentamento (EA); Programa de Formação de Jovens Empresários Rurais (PROJOVEM); Escolas Técnicas Estaduais (ETE); Casas das Famílias Rurais (CDFR); Centro de Desenvolvimento do Jovem Rural (CDEJOR). Vale destacar que, dentre estas, nem todas se organizarão como escolas, pois algumas não oferecem educação escolar.

Para Queiroz (2004) ainda é possível encontrar três tipos de alternância nesses centros:

a) Alternância justa positiva: Tendo como característica a sucessão dos tempos ou períodos consagrados ao trabalho e ao estudo, sem que haja uma relação entre eles;

b) Alternância associativa: Associação de fato entre a formação geral e a formação profissional, relacionando a atividade escolar e a atividade profissional, mas ainda como simples adição;

c) Alternância Integrativa real ou copulativa: Compenetração efetiva de meios de vida sócio profissional e escolar em uma unidade de tempos formativos, buscando a completa conexão entre os dois, sem que haja sobreposição de um sobre o outro. Assim, o aluno alterna entre períodos de aprendizado na família e períodos na escola, buscando a interligação através de instrumentos pedagógicos específicos de forma harmoniosa.

A duração das atividades de formação varia de três a quatro anos:

O método de alternância ocorre por meio de períodos em que os alunos passam na família/comunidade, duas semanas, alternando com outro período de uma semana (CFR) ou duas semanas (EFA) no centro de formação, isso é, na escola (SECADI, 2012, p.42).

Dentro desta perspectiva, os objetivos dos CEFFA são: a formação integral dos jovens para o meio rural, buscando sempre a adequação a sua realidade; a melhoria da qualidade de vida a partir da aplicação de conhecimentos técnicos-científicos; além de estimular o maior contato com a comunidade local (SECADI, 2012). Lima et.al. (2013) diz que: 


\begin{abstract}
A pedagogia da alternância utiliza instrumentos pedagógicos que integram o conhecimento científico ao conhecimento prático, valorizando as experiências e fortalecendo os vínculos sociais. O ponto auge da Pedagogia da Alternância é a relação escola/família/aluno e sociedade. Existe a integração de todos os elementos na elaboração do Plano de Estudo e do enfoque educacional. $\mathrm{O}$ objetivo é a formação integral do jovem, o desenvolvimento econômico e social do campo (LIMA et.al., 2013, p.2970).
\end{abstract}

Agora buscando uma análise teórica, a Pedagogia da Alternância, como dito por Gimonet (2007), se aproxima muito da ideia defendida por Paulo Freire centrada na educação como processo de conscientização e de conquista da liberdade por meio da participação direta do sujeito histórico para a responsabilidade social e política. A Pedagogia da Alternância começa na "experiência da vida cotidiana (familiar, profissional, social) para ir em direção à teoria, aos saberes dos programas acadêmicos, para em seguida, voltar à experiência, e assim sucessivamente" (GIMONET, 2007, p.16). Para Nosella (2012):

Com efeito, trata-se de uma metodologia que criou uma didática específica para articular dialeticamente os saberes escolares com os saberes da experiência fora da escola. Assim, trata-se de uma metodologia nascida do meio rural, mas que o transcende, pois, toda relação pedagógica é uma dialética integradora entre o saber escolar e os saberes da vida. Por isso, mais que uma metodologia, trata-se de um novo sistema escolar (NOSELLA, 2012, p.48 apud LIMA, et.al., 2013, p.2972).

A partir de uma alternância efetiva (alternância integrativa real ou copulativa) o jovem do meio rural deixa de ser um simples aluno da escola e passa a ser um sujeito ativo e inserido no contexto espaço/tempo/território que ele está presente (GIMONET, 2007). Portanto, a Pedagogia da Alternância foi elaborada "não a partir de teorias, mas pela invenção e implementação de um instrumental pedagógico que traduzia, nos seus atos, o sentido e os procedimentos de formação" (GIMONET, 2007, p.23 apud LIMA, et.al., 2013, p.2980), em uma completa harmonia entre a teoria e a prática. Segundo Gimonet (2007):

Com a Pedagogia da Alternância deixa-se para trás uma pedagogia plana para ingressar numa pedagogia do espaço e no tempo diversificam-se as instituições, bem como os autores implicados. Os papeis destes não são mais aqueles da escola costumeira. O jovem (pré-adolescente, adolescente ou jovem adulto) em formação, isto é, o alterante, não é mais um aluno da escola, mas já um ator num determinado contexto de vida e num território. Sua família é convidada a participar ativamente de sua educação, de sua formação, acima de tudo porque é jovem (GIMONET, 2007, p.20).

Esta relação entre a teoria (conhecimento científico) e a prática (conhecimento tácito), usando os termos que Lima et. al. (2013) usa em seu texto, possibilita relacionar com a práxis de Marx, no qual:

A práxis no sentido que Marx atribui, ação transformadora revolucionária, transcendente a condição de simples ação. Contudo, não expressa qualquer ação transformadora, posto que está aprofundada numa concepção dialética da história e da sociedade, une pensamento consciente e ação real, com vistas a transformação radical da sociedade. Isso porque, a práxis torna possível a passagem da teoria à prática, essencialmente, uma prática transformadora, revolucionária. (BATISTA, 2007, p.177) 
Portanto, a alternância possibilita a transformação do simples aluno em um sujeito ativo e consciente da problemática da classe na qual está inserido, portando uma visão crítica propiciada por uma teoria científica e uma prática do real, das necessidades efetivas do seu contexto familiar e local. A práxis geradora desta relação é uma condição crucial para que haja uma autonomia no sentido que Castoriadis atribuía. Assim sendo, é condição também para um desenvolvimento socioespacial que irá se contrapor a uma educação hegemônica e urbanoide. Assim, caracteriza as escolas do campo como espaços de resistência ou "territórios dissidentes" como proposto por Marcelo Lopes de Souza, assim como, espaços de economias solidárias, heterotopia e contra espaços como já proposto neste texto.

\section{Considerações Finais}

Para fins de conclusão, este artigo busca articulações entre o conteúdo teórico acerca do ambientalismo, da educação ambiental, e da educação do campo com a geografia crítica ou radical e seu viés pela busca por transformação da sociedade. Dialogando com conceitos como "espaço de resistência" (SOUZA, 2013), "contra espaço" (MOREIRA, 2012), "heterotopia" (FOUCAULT, 2013) e "economia solidária" (MENDES \& ORTIGOZA, 2015), evidencia-se propostas pedagógicas consideradas "dissidentes". Propostas estas que exemplificariam de maneira mais prática e concreta potenciais de resistências possíveis engendradas pelos movimentos sociais vinculados à educação do campo no Brasil que poderiam se contrapor a uma educação considerada hegemônica da sociedade atual.

Concluiu-se, ao longo do texto, que tanto o PRONERA - Programa Nacional de Educação na Reforma Agrária - quanto os Centros Familiares de Formação por Alternância (CEFFAs) podem sim ser consideradas propostas educativas dissidentes, pois ambas irão se contrapor a uma educação hegemônica criando, consequentemente, espaços de resistência ou "territórios dissidentes" como proposto por Marcelo Lopes de Souza, assim como, "espaços de economias solidárias", "heterotopia" e "contra espaços", conforme os autores citados.

No caso do PRONERA, foram estabelecidas explicitamente políticas educacionais para o campo, e dele surgiram novas ideias e metodologias pedagógicas que se propuseram a confrontar uma lógica educacional já (im)posta. No que se refere aos CEFFAs, os mesmos também são considerados dissidentes, pois a alternância possibilitou a transformação do "simples" aluno um sujeito ativo e consciente da problemática de classe na qual está inserido. Portanto, tenciona uma visão crítica, propiciada por uma teoria científica e uma prática do real, das necessidades reais do seu contexto familiar e local.

\section{Nota}

1 - Para Marcelo Lopes de Souza a noção de heteronomia se refere à assimetria estrutural de poder entre dirigentes e dirigidos, dominantes e dominados (SOUZA, 2013).

\section{Referências Bibliográficas}

ALIER, J. M. O ecologismo dos pobres: conflitos ambientais e linguagens de valoração. São Paulo: Contexto, 2007. 
BATISTA, A. M. de M. Práxis, consciência de práxis e educação popular: algumas reflexões sobre suas conexões. Educ. e Filos., Uberlândia, v. 21, n. 42, p. 169-192, jul./dez. 2007.

BRASIL. Dias letivos para aplicação da pedagogia nos Centros Familiares de Formação por Alternância (CEFFA). Brasília: SECAD/MEC, 2016.

BRASIL. Programa Nacional de Educação na Reforma Agrária. Manual de Operações, 2014. Brasília: MDA/INCRA, 2014.

BRASIL. Educação do Campo: marcos normativos. Brasília: SECAD/MEC, 2012.

CALDART, R. S. Educação do campo: notas para uma análise de percurso. Trab. Educ. Saúde, Rio de Janeiro, v.7 n.1, p. 35-64, mar./jun. 2009.

CALDART, R, S. Por uma educação do campo: traços de uma identidade em construção. In: ARROYO, M, G.; CALDART, R. S.; MOLINA, M. C. (Org.). Por uma Educação do Campo. Petrópolis: Vozes, 2004.

CARNEIRO, M. E. F. et. al. Educação e política pública: caminhos históricos do PRONERA. Educativa, Goiânia, v. 19, n. 1, p. 233-258, jan./abr. 2016.

CASTORIADIS, C. A instituição imaginária da sociedade. Rio de Janeiro: Paz e Terra, 1991.

FERNANDES, B. M. \& TARLAU, R. Razões para mudar o mundo: a educação do campo e a contribuição do PRONERA. Educ. Soc., Campinas, v.38, n ${ }^{\circ}$ 140, p. 545-567, jul.- set., 2017.

FOUCAULT, M. De espaços outros. Estudos avançados, São Paulo, v. 27, n. 79, p. 113122, jan. 2013.

GIMONET, J.C Praticar e compreender a pedagogia da alternância dos CEFFAs. Petrópolis: Editora Vozes; Paris: AIMFR, 2007.

LAYRARGUES \& LIMA. Mapeando as macro-tendências político-pedagógicas da educação ambiental contemporânea no Brasil. VI Encontro: Pesquisa e Educação Ambiental, A pesquisa em Educação Ambiental e a Pós-Graduação no Brasil. Ribeirão Preto, set. 2011.

LEFEBVRE, H. A produção do espaço. Trad. Doralice Barros Pereira e Sérgio Martins (do original: La production de l'espace. 4e éd. Paris: Éditions Anthropos, 2000).

LEFF, E. A aposta pela vida: imaginação sociológica e imaginários sociais nos territórios ambientais do sul. Petrópolis: Vozes. 2016.

LIMA, H. R., et.al. A pedagogia da alternância: aproximações teóricas possíveis. XI Congresso Nacional de Educação - EDUCERE. PUC-PR (Editora), Curitiba, 2013.

MARTINS, A. M. Autonomia e educação: a trajetória de um conceito. Cadernos de Pesquisa, n. 115, p. 207-232, março/2002.

MENDES, A. A.; ORTIGOZA, S. A. G. Economia solidária, práticas espaciais e territórios dissidentes em Rio Claro - SP. In: I CONPES - Congresso de Pesquisadores de Economia Solidária, 2015. Desafios globais do trabalho com mediação solidária. São Carlos: UFSCar, 2015. v. 1. p. 1-30. 
MENDONÇA, F. Geografia e meio ambiente. (9. ed.). São Paulo: Contexto, 2012.

MOREIRA, Ruy. Geografia e Práxis. A presença do espaço na teoria e na prática geográficas. São Paulo: Contexto, 2012.

NOSELLA, P. As origens da pedagogia da alternância no Brasil. Vitória: EDUFES, 2012.

OLIVEIRA, M. C. de. As jornadas de junho/2013, Porto Alegre/RS: Os movimentos sociais e as formas simbólicas na formação de territórios dissidentes. Dissertação (Mestrado em Geografia). Porto Alegre: Universidade Federal do Rio Grande do Sul, Instituto de Geociências, 2018.

QUEIROZ, J. B. P. de. Construção das Escolas Familiares Agrícolas no Brasil: ensino médio e educação Profissional. Tese (Doutorado em Sociologia). Brasília: Universidade de Brasília, Programa de Pós-Graduação em Sociologia, 2004.

SANTOS, D. M. S. \& SILVA, N. O. Educação na reforma agrária: a experiência do PRONERA e os 19 anos de luta e revolução. VIII Jornada Internacional Políticas Públicas, Centro de Ciências Humanas/Programa de Pós-Graduação em Políticas Públicas, Universidade Federal do Maranhão, Maranhão, 2017.

SILVA, L. H. A pedagogia da alternância na educação do campo: velhas questões, novas perspectivas de estudos. EccoS - Ver. Cient., São Paulo, n. 36, p. 143-158, jan./abr. 2015.

SOUZA, M. J. L. de. Os conceitos fundamentais da pesquisa sócio-espacial. Rio de Janeiro: Bertrand Brasil, 2013.

TRES, L. A resistência como práxis dos movimentos ambientalistas e ecológicos. Práxis Educativa, Ponta Grossa, v. 1, n. 1, p.67-76, jun. 2006. 